\title{
Evaluation of the anticancer activities of thioflavanone and thioflavone in human breast cancer cell lines
}

\author{
EUN JEONG CHOI, JAE IN LEE and GUN-HEE KIM \\ Plant Resources Research Institute, Duksung Women's University, Tobong-ku, Seoul 132-714, Republic of Korea
}

Received August 29, 2011; Accepted October 7, 2011

DOI: $10.3892 / \mathrm{ijmm} .2011 .834$

\begin{abstract}
This study investigated the anticancer effects of thioflavanone and thioflavone in the MCF-7, MDA-MB-231 and MDA-MB-453 human breast cancer cell lines. Cells were treated with either thioflavanone or thioflavone from 1 to $100 \mu \mathrm{M}$ for $24 \mathrm{~h}$, and their anti-proliferative activity and cytotoxicity was determined. Thioflavanone and thioflavone possessed similar anti-proliferative activities; their $\mathrm{IC}_{50}$ values were $62-89$ and $74-128 \mu \mathrm{M}$, respectively, although the cytotoxicity of thioflavanone was significantly higher and occurred in a dose-dependent manner. Taken together, these results suggest that thioflavanone significantly inhibits cellular proliferation with weak cytotoxicity to a greater extent than thioflavone, and induces apoptosis in human breast cancer cell lines. Moreover, thioflavanone, but not thioflavone, induces apoptosis via p53-dependent expression of Bax.
\end{abstract}

\section{Introduction}

Flavonoids are a group of over 6,000 phytochemicals that include flavones, flavonols, flavanones, and isoflavones in palnts, and are usually present almost exclusively in the form of $\beta$-glycosides. According to several epidemiological studies, flavonoids may reduce the risk of developing cancer and cardiovascular disease (1-3). Due to their benefit to human health, the biological activity of flavonoids has been extensively examined in terms of their antitumor, anti-inflammatory, and antioxidant capacity in vitro $(4,5)$.

The common structural feature of flavonoids is the flavan nucleus, which consists of 15 carbon atoms arranged in 3 rings (phenylchromanone structure, C6-C3-C6). Rings A and B are benzene rings and ring $\mathrm{C}$ is a heterocyclic pyran or pyrone. A number of the anticancer mechanisms of flavonoids have been shown to be associated with their structure-activity

Correspondence to: Professor Gun-Hee Kim, Plant Resources Research Institute, Duksung Women's University, 419 Ssangmun-dong, Tobong-ku, Seoul 132-714, Republic of Korea

E-mail: ejchoi@duksung.ac.kr

Key words: anticancer, cytotoxicity, thioflavanone, thioflavone, human breast cancer relationships (SAR) (6). Recently, much research has aimed to understand the relationship between structural modifications and biological activity. In an attempt to increase anticancer activity, the synthesis of new flavonoid analogues has been conducted (7). Moreover, the anticancer activity of these synthetic compounds has been observed in various cancer cell lines in vitro (8-13). We previously reported the production of synthetic flavonoids (14-16) that exert various biological activities in vitro (17). Sulfur-containing flavonoid analogues have activities greater than the molecules from which they were derived. For example, synthetic thioflavopiridols may act as selective CDK1 inhibitors in human tumor cell lines (18). Our previous report (17) suggested that synthetic flavanone derivatives were more potent than flavanone in an antiproliferation assay using human breast cancer cells.

In the present study, we investigated the anticancer activities of thioflavanone and thioflavone in vitro. We postulated that thioflavanone and thioflavone, which are synthesized as the thio analogues, may possess greater biological activities than their precursors.

\section{Materials and methods}

Synthesis of thioflavanone and thioflavone. Treatment of thiosalicylic acid (denoted as 1 in Fig. 1) with 3 equiv of methyllithium in dimethoxyethane (DME) afforded 2'-mercaptoacetophenone (denoted as 2 in Fig. 1) at an $80 \%$ yield after acidic workup. The direct condensation of 2 with benzaldehyde was accomplished with 2 equiv of lithium diisopropylamide (LDA) in THF for $2 \mathrm{~h}$ between $-15^{\circ} \mathrm{C}$ and room temperature. The addition of benzaldehyde to a solution of the dilithiated anion, generated from 2 and 2 equiv of LDA in THF for $1 \mathrm{~h}$ at $-15^{\circ} \mathrm{C}$, afforded the corresponding chalcone and the successive nucleophilic attack of sulfur anion to the $\beta$-carbon intramolecularly to give thioflavanone (denoted as 3 in Fig. 1) at an $87 \%$ yield, accompanied by elimination of lithium hydroxide.

The reaction of the dilithiated anion of 2 with $N$-methoxy- $N$-methyl benzamide proceeded for $16 \mathrm{~h}$ at room temperature to give 1-(2-mercaptophenyl)-3-phenyl1,3-propanedione (denoted as 4 in Fig. 1) in $84 \%$ yield after acidic hydrolysis. The cyclodehydration of 4 proceeded well with $\mathrm{H}_{2} \mathrm{SO}_{4}$ in $\mathrm{CH}_{3} \mathrm{CN}$ within $1 \mathrm{~h}$ at room temperature to give thioflavone (denoted as 5 in Fig 1) at a $94 \%$ yield.

Thioflavanone: $\mathrm{mp} 56-57^{\circ} \mathrm{C}$; ${ }^{1} \mathrm{H}$ NMR (300 $\mathrm{MHz}, \mathrm{CDCl}_{3}$ ) $\delta 8.15\left(\mathrm{dd}, J_{1}=8.0 \mathrm{~Hz}, J_{2}=1.3 \mathrm{~Hz}, 1 \mathrm{H}\right), 7.31-7.46(\mathrm{~m}, 6 \mathrm{H}), 7.18-7.31$ 


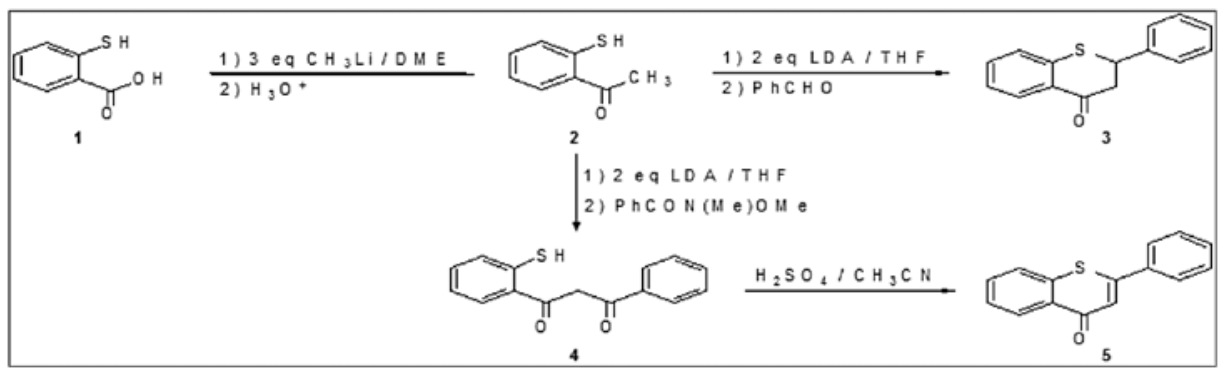

Figure 1. Synthesis of thioflavanone and thioflavone.

$(\mathrm{m}, 2 \mathrm{H}), 4.72\left(\mathrm{dd}, J_{1}=12.8 \mathrm{~Hz}, J_{2}=3.3 \mathrm{~Hz}, 1 \mathrm{H}\right), 3.32\left(\mathrm{dd}, J_{1}=16.4\right.$ $\left.\mathrm{Hz}, J_{2}=12.8 \mathrm{~Hz}, 1 \mathrm{H}\right), 3.20\left(\mathrm{dd}, J_{1}=16.4 \mathrm{~Hz}, J_{2}=3.3 \mathrm{~Hz}, 1 \mathrm{H}\right)$; ${ }^{13} \mathrm{C} \mathrm{NMR}\left(75 \mathrm{MHz}, \mathrm{CDCl}_{3}\right) \delta 194.4,142.1,138.4,133.7,130.4$, 129.2, 129.0, 128.5, 127.4, 127.2, 125.2, 46.7, 45.5; FT-IR (KBr) 3060, 2946, 1677 (C=O), 1586, 1435, 1285, 1085, 756, 697 $\mathrm{cm}^{-1}$; Ms m/z (\%) $240\left(\mathrm{M}^{+}, 51\right), 163$ (20), 136 (100), 108 (50), 97 (33), 83 (33).

Thioflavone: $\mathrm{mp} 125-126^{\circ} \mathrm{C} ;{ }^{1} \mathrm{H}$ NMR $\left(300 \mathrm{MHz}, \mathrm{CDCl}_{3}\right)$

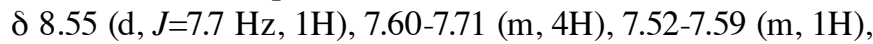
7.48-7.52 (m, 3H), $7.24(\mathrm{~s}, 1 \mathrm{H}) ;{ }^{13} \mathrm{C} \mathrm{NMR}\left(75 \mathrm{MHz}, \mathrm{CDCl}_{3}\right.$ ) ठ 180.8, 153.0, 137.7, 136.5, 131.6, 130.9, 130.8, 129.3, 128.6, 127.8, 126.9, 126.5, 123.4; FT-IR (KBr) 3066, $1620(\mathrm{C}=\mathrm{O})$, 1587, 1335, 1098, 759, $696 \mathrm{~cm}^{-1} ; \mathrm{Ms} \mathrm{m} / \mathrm{z}(\%) 238\left(\mathrm{M}^{+}, 100\right), 210$ (95), 136 (46), 108 (22).

Cell culture. Chinese hamster ovary $\mathrm{CHO}-\mathrm{K} 1$ cell line and human breast cancer cell lines such as MCF-7, MDA-MB-231 and MDA-MB-453 were purchased from the KCLB (Korean Cell Line Bank, Korea). Cells were routinely maintained in RPMI-1640 (Invitrogen, Carlsbad, USA), supplemented with $10 \%$ fetal bovine serum (FBS) and antibiotics $(50 \mathrm{U} / \mathrm{ml}$ of penicillin and $50 \mu \mathrm{g} / \mathrm{ml}$ streptomycin, Gibco) at $37^{\circ} \mathrm{C}$ in a humidified atmosphere containing $5 \% \mathrm{CO}_{2}$.

MTT assay. Each cell line was plated at a density of $1 \times 10^{5}$ cells/well in 96-well tissue culture plate (Corning, NY, USA), and incubated at $37^{\circ} \mathrm{C}$ for $24 \mathrm{~h}$. Plated cells were treated with indicated concentrations of either thioflavanone or thioflavone for $24 \mathrm{~h}$. After treatment, plated cell were incubated with 3-(4, 5-dimethylthiazol-2-yl)-2,5-diphenyltetrazolium bromide (MTT, Sigma Chemical Company, $0.5 \mathrm{mg} / \mathrm{ml}$ final concentration) for $4 \mathrm{~h}$ at $37^{\circ} \mathrm{C}$. After discarding all the medium from the plates, $100 \mu \mathrm{l}$ of dimethyl sulfoxide (DMSO) was added to the each well. The plates were placed for $5 \mathrm{~min}$ at room temperature with shaking, so that complete dissolution of formazan was achieved. The absorbance of the MTT formazan was determined at $540 \mathrm{~nm}$ by a UV spectrophotometric plate reader (EMax; Molecular Devices, Sunnyvale, CA, USA). The value of $\mathrm{IC}_{50}$ (i.e., the concentration of the extract required to inhibit cancer cell growth by $50 \%$ of levels in control compound solvent-treated only cells) was estimated from the plot. Each $\mathrm{IC}_{50}$ of thioflavanone on human breast cancer cell lines was applied for the assay of apoptosis detection.

Lactate dehydrogenase $(\mathrm{LDH})$ release assay. The cytotoxicity of either thioflavanone or thioflavone in CHO-K1 cells was assessed by measuring the release of the enzyme LDH using an LDH cytotoxicity Detection kit (Cat. no. 630117 Takara Korea Biomedical, Inc., Korea).

DAPI staining assay. Apoptotic morphological changes were determined by DAPI (4',6-diamidino-2-phenyl-indole) staining. After harvesting the cells exposed with apigenin for $72 \mathrm{~h}$, the cells were seeded in poly-l-lysine coated slides and fixed with $4 \%$ methanol-free formaldehyde solution for $30 \mathrm{~min}$. Then mounting medium with DAPI (Molecular Probes, Eugene, OR) was dispersed over the entire section of slides. Mounted slides were stored at $4{ }^{\circ} \mathrm{C}$ without light. Each slide was observed under AxioVision 4.0 fluorescence microscopes (Carl Zeiss, Inc., USA). Additionally, features of MDA-MB-453 cells exposed to apigenin were also observed using a Nikon inverse phase contrast microscope (Nikon TMS, Nikon, Japan) equipped with an objective (Plan 10/0.30DL/ Ph1, Nikon, Japan) of x100 magnification.

Statistical analyses. All the data are expressed as percent compared with vehicle-treated control cells, which were arbitrarily assigned $100 \%$. Data were analyzed by one-way analysis of variance followed by the Dunnett's multiple comparison test (SigmaStat, Jandel, San Rafael, USA). For all comparisons, differences were considered statistically significant at $\mathrm{P}<0.05$.

\section{Results}

Antiproliferative activity of thioflavanone and thioflavone on human breast cancer cell lines. The effects of thioflavanone and thioflavone on cell proliferation were measured using the MTT assay, in 3 human breast cancer cell lines (MCF-7, MDA-MB-453, and MDA-MB-231) exposed to either thioflavanone or thioflavone between 1 and $100 \mu \mathrm{M}$ for $24 \mathrm{~h}$ (Fig. 2). Both thioflavanone and thioflavone significantly inhibited cancer cell growth in a dose-dependent manner $(\mathrm{P}<0.05)$. The $\mathrm{IC}_{50}$ values of thioflavanone in MCF-7, MDA-MB-453, and MDA-MB-231 cells were 63.8, 88.9, and 62.2 $\mu \mathrm{M}$, respectively; the $\mathrm{IC}_{50}$ values of thioflavone were higher than those of thioflavone.

Cytotoxicity of thioflavanone and thioflavone. The cytotoxicity of thioflavanone and thioflavone was determined by measuring the release of lactate dehydrogenase (LDH) by CHO-K1 cells (Fig. 3). Although thioflavone significantly increased LDH release, as compared to controls, thioflavanone had an effect on LDH release only at concentrations greater than $100 \mu \mathrm{M}$. The highest cytotoxicity of thioflavanone was 

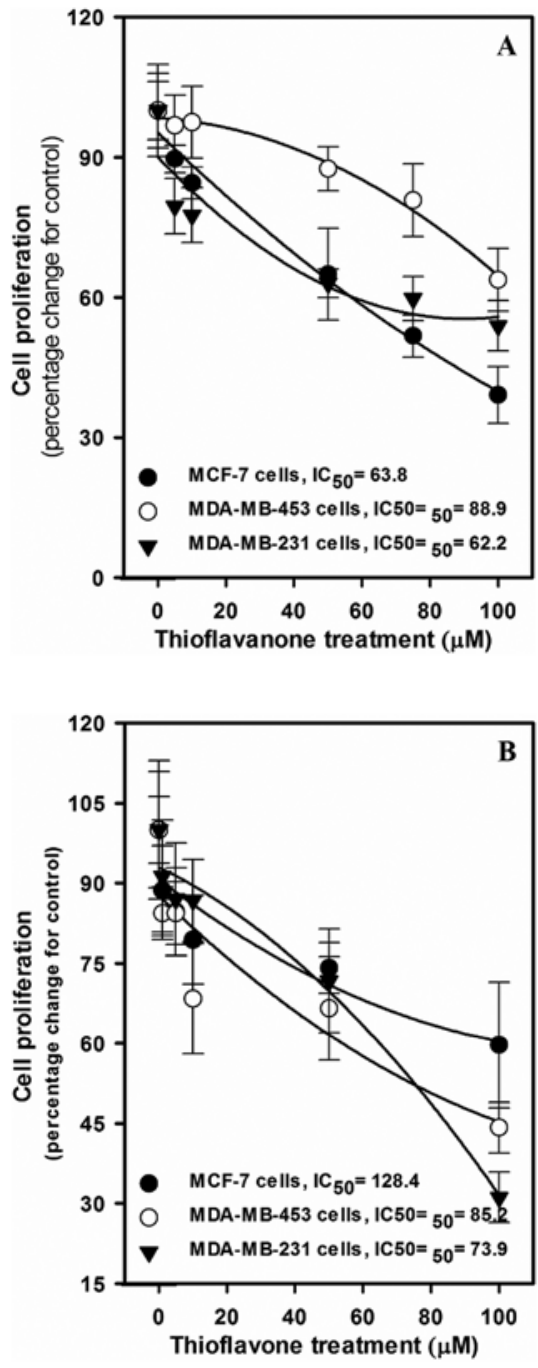

Figure 2. Antiproliferative activity of either (A) thioflavanone or (B) thioflavone.

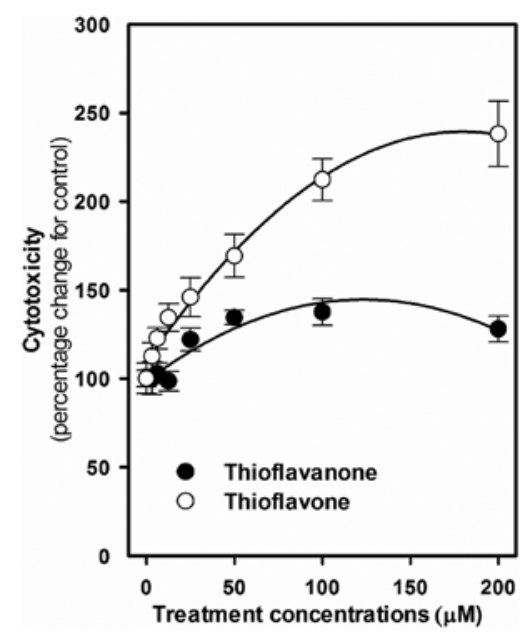

Figure 3. Cytotoxicity of thioflavanone and thioflavone.

observed at $100 \mu \mathrm{M}$ (an increase of 137.8\%). Treatment with $6.25 \mu \mathrm{M}$ thioflavone induced significant cytotoxicity, which continuously increased in dose-dependent manner (increases of 212.3 and $238.2 \%$ at 100 and $200 \mu \mathrm{M}$, respectively).

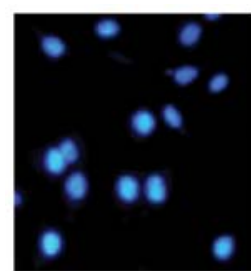

MCF-7 cells

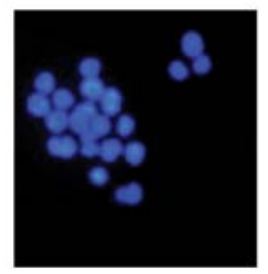

MDA-MB-453 cells

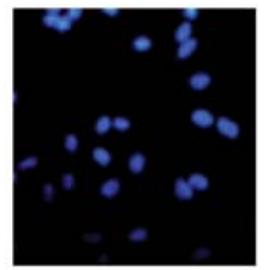

MDA-MB-231 cells

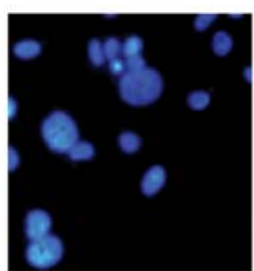

Thioflavanone

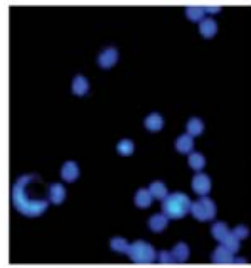

Thioflavanone

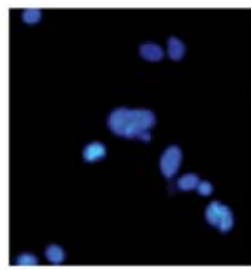

Thioflavanone

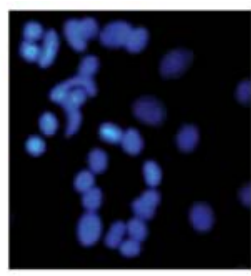

Thioflavone

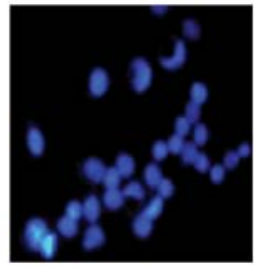

Thioflavone

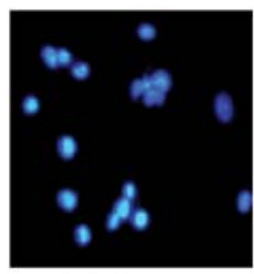

Thioflavone
Figure 4. Apoptosis induction by thioflavanone and thioflavone.

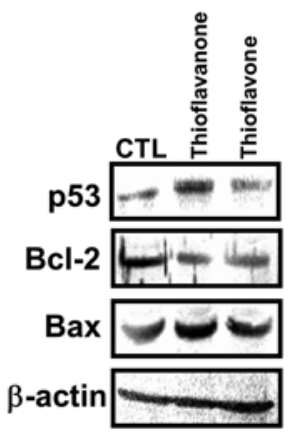

Figure 5. Expression of p53, Bcl-2 and Bax in MDA-MB-231 cells exposed to either thioflavanone or thioflavone.

Apoptosis induction by thioflavanone and thioflavone. DAPI staining was used to detect apoptotic changes after exposing cells to either thioflavanone or thioflavone at their $\mathrm{IC}_{50}$ concentrations (Fig. 4). Apoptotic morphological features such as cell shrinkage and dot-shaped nuclear fragments were observed after exposure of cells to both thioflavanone and thioflavone. Compared to respective controls, exposure to thioflavanone resulted in a remarkable increase in apoptotic morphological features. These data suggest that thioflavanone may possess anticancer properties.

Apoptosis-related gene expression by thioflavanone and thioflavone. We used MDA-MB-231 cells to investigate the apoptosis induced by thioflavanone and thioflavone, since proliferation assays suggested that these cells were affected to the greatest extent (Fig. 5). Activation of p53 was observed 
after treatment with thioflavanone at its $\mathrm{IC}_{50}$ for $24 \mathrm{~h}$. Bcl-2 expression was lower and that of Bax higher in MDA-MB231 cells exposed to both thioflavanone and thioflavone.

\section{Discussion}

Breast cancer is one of the most frequently diagnosed cancers in women and its occurrence has, in recent years, increased worldwide. The present study evaluated the anticancer activity of the synthetic anticancer drug candidate thioflavanone and thioflavone in human breast cancer cell lines.

We first determined the antiproliferative effect of thioflavanone and thioflavone, on the human breast cancer cell lines MCF-7,MDA-MB-453, and MDA-MB-231. Both thioflavanone and thioflavone significantly inhibited cellular proliferation in all 3 cell lines in a dose-dependent manner. The $\mathrm{IC}_{50}$ ranges of thioflavanone and thioflavone were observed to be $62-89 \mu \mathrm{M}$ and $74-129 \mu \mathrm{M}$, respectively in the 3 cell lines. Although it has been reported that flavone is more efficient than flavanone in breast cancer cells $(19,20)$, in this study their activities were similar. However, exposure to thioflavone induced a cytotoxic effect as determined by $\mathrm{LDH}$ release, in the $\mathrm{CHO}-\mathrm{Kl}$ cell line. This cytotoxicity increased in a dose-dependent manner, and was over 1.9 times greater than that of thioflavanone. Based on these results, thioflavanone may be a more appropriate anticancer drug candidate, and has the potential to selectively inhibit cancer growth.

Moreover, thioflavanone and thioflavone induced apoptosis in the human breast cancer cell lines examined when exposed at their $\mathrm{IC}_{50}$ concentrations. Several studies have indicated that anticancer drugs or cancer chemopreventive agents act through the induction of apoptosis in various cancer cells. In addition, the initiation of apoptosis appears to be a common mechanism of many new anticancer agents $(21,22)$.

As a brief study of the underlying mechanism, the expression of a few apoptosis-related genes was investigated in MDA-MB-231 cells exposed to thioflavanone and thioflavone at their $\mathrm{IC}_{50}$ for $24 \mathrm{~h}$. Activation of p53 in response to DNA damage led to cell cycle arrest and inhibition of cell proliferation (23,24). p53 acts as a sequence-specific binding protein and may be regulated by Bax, a member of the Bcl-2 family $(25,26)$. Members of the Bcl-2 family of proteins are critical regulators of the apoptotic pathway, and consist of the major antiapoptotic proteins, $\mathrm{Bcl}-\mathrm{x}_{\mathrm{L}}$ and $\mathrm{Bcl}-2$, and the major proapoptotic proteins, Bax and Bak (27). It has been reported that an increase in Bax expression by p53 overexpression correlates with the induction of apoptosis in several cell types (25-28). Based on these results, thioflavanone, but not thioflavone, may induce apoptosis through the p53-dependent expression of Bax. Although both thioflavanone and thioflavone induced apoptosis in MDA-MB-231 cells at their respective $\mathrm{IC}_{50}$ value, thioflavanone and thioflavone may act through different pathways, which may explain the cytotoxic effect of thioflavone. That is, thioflavanone may act through multiple pathways to induce apoptosis.

In conclusion, our results indicate that thioflavanone significantly inhibited cellular proliferation with a weak cytotoxicity and induced apoptosis in human breast cancer cell lines. Moreover, we speculate that the mechanism by which thioflavanone induced apoptosis was through a p53-dependent pathway. The induction of apoptosis by thioflavanone may be a novel strategy for cancer chemotherapy.

\section{Acknowledgements}

This study was supported by the Priority Research Centers Program through the National Research Foundation of Korea (NRF) funded by the Ministry of Education, Science and Technology (2010-0029692).

\section{References}

1. Brown DM, Kelly GE and Husband AJ: Flavonoid compounds in maintenance of prostate health and prevention and treatment of cancer. Mol Biotechnol 30: 253-270, 2005.

2. Gates MA, Vitonis AF, Tworoger SS, Rosner B, Titus-Ernstoff L, Hankinson SE and Cramer DW: Flavonoid intake and ovarian cancer risk in a population-based case-control study. Int J Cancer 24: 1918-1925, 2009.

3. Peterson J, Lagiou P, Samoli E, Lagiou A, Katsouyanni K, La Vecchia C, Dwyer J and Trichopoulos D: Flavonoid intake and breast cancer risk: a case control study in Greece. Br J Cancer 89: 1255-1259, 2003

4. Benavente-García O and Castillo J: Update on uses and properties of citrus flavonoids: new findings in anticancer, cardiovascular, and anti-inflammatory activity. J Agric Food Chem 56: 6185-6205, 2008.

5. Iwashina T: Flavonoid function and activity to plants and other organisms. Biol Sci Space 17: 24-44, 2003.

6. Pick A, Müller H, Mayer R, Haenisch B, Pajeva IK, Weigt M, Bönisch H, Müller CE and Wiese M: Structure-activity relationships of flavonoids as inhibitors of breast cancer resistance protein (BCRP). Bioorg Med Chem 19: 2090-2102, 2011.

7. Wang HK, Xia Y, Yang ZY, Natschke SL and Lee KH: Recent advances in the discovery and development of flavonoids and their analogues as antitumor and anti-HIV agents. Adv Exp Med Biol 439: 191-225, 1998.

8. Zhang LB, Qiang L, Chen FH, Wu T, Rong JJ, Zhao Q, Zou MJ, Yang Z, You QD, Li ZY, Wu YL and Guo QL: DHF-18, a new synthetic flavonoid, induced a mitochondrial-mediated apoptosis of hepatocarcinoma cells in vivo and in vitro. Eur J Pharmacol 651: 33-40, 2011.

9. Chen HM, Chang FR, Hsieh YC, Cheng YJ, Hsieh KC, Tsai LM, Lin AS, Wu YC and Yuan SS: A novel synthetic protoapigenone analogue, WYC02-9, induces DNA damage and apoptosis in DU145 prostate cancer cells through generation of reactive oxygen species. Free Radic Biol Med 50: 1151-1162, 2011.

10. Liu YL, Ho DK, Cassady JM, Cook VM and Baird WM: Isolation of potential cancer chemopreventive agents from Eriodictyoncalifornicum. J Nat Prod 55: 357-363, 1992.

11. Min BS, Chung KS and Bae KH: Antitumor activity of 2(S)-5, 2',5'trihydroxy-7,8-dimethoxyflavanone and its analogues. Arch Pharm Res 20: 368-371, 1997.

12. Choi YJ, Lee MK, Lee YJ, Jeong YJ, Yoon Park JH, Sung Lim S and Kang YH: Inhibition of hydrogen peroxide-induced endothelial apoptosis by 2',4',7-trihydroxyflavanone, a flavonoid form. J Med Food 7: 408-416, 2004.

13. Ying $\mathrm{M}, \mathrm{Tu} \mathrm{C}$, Ying $\mathrm{H}, \mathrm{Hu} \mathrm{Y}, \mathrm{He} \mathrm{Q}$ and Yang B: MSFTZ, a flavanone derivative, induces human hepatoma cell apoptosis via a reactive oxygen species- and caspase-dependent mitochondrial pathway. J Pharmacol Exp Ther 325: 758-765, 2008.

14. Lee JI and Jung MG: A new route for the synthesis of flavanones from 2-methoxybenzoic acids. Bull Korean Chem Soc 26: 2044-2046, 2005.

15. Lee JI, Jung MG and Jung HJ: A novel synthesis of flavanones from 2-hydroxybenzoic acids. Bull Korean Chem Soc 28: 859-862, 2007.

16. Lee JI: A new synthesis of thioflavanones from thiosalicylic acid. Bull Korean Chem Soc 29: 1263-1265, 2008.

17. Choi EJ, Lee JI and Kim GH: Anti-carcinogenic effect of a new analogue 4'-chloroflavanone from flavanone in human breast cancer cells. Int J Mol Med 25: 293-298, 2010.

18. Kim KS, Sack JS, Tokarski JS, Qian L, Chao ST, Leith L, Kelly YF, Misra RN, Hunt JT, Kimball SD, Humphreys WG, Wautlet BS, Mulheron JG and Webster KR: Thio- and oxoflavopiridols, cyclin-dependent kinase 1-selective inhibitors: synthesis and biological effects. J Med Chem 43: 4126-4134, 2000. 
19. Ahmed-Belkacem A, Pozza A, Muñoz-Martínez F, Bates SE, Castanys S, Gamarro F, Di Pietro A and Pérez-Victoria JM: Flavonoid structure-activity studies identify 6-prenylchrysin and tectochrysin as potent and specific inhibitors of breast cancer resistance protein ABCG2. Cancer Res 65: 4852-4860, 2005.

20. Leopoldini M, Russo N and Toscano M: A comparative study of the antioxidant power of flavonoid catechin and its planar analogue. J Agric Food Chem 55: 7944-7949, 2007.

21. Hersey P and Zhang XD: Overcoming resistance of cancer cells to apoptosis. J Cell Physiol 196: 9-18, 2003.

22. Tsuruo T, Naito M, Tomida A, Fujita N, Mashima T, Sakamoto H and Haga N: Molecular targeting therapy of cancer: drug resistance, apoptosis and survival signal. Cancer Sci 94: 15-21, 2003.

23. Liebermann DA, Hoffman B and Steinman RA: Molecular controls of growth arrest and apoptosis: p53-dependent and independent pathways. Oncogene 11: 199-210, 1995.

24. Lepik D,Jaks V, Kadaja L, Värv S and Maimets T: Electroporation and carrier DNA cause p53 activation, cell cycle arrest, and apoptosis. Anal Biochem 318: 52-59, 2003.
25. McCurrach ME, Connor TM, Knudson CM, Korsmeyer SJ and Lowe SW: Bax-deficiency promotes drug resistance and oncogenic transformation by attenuating p53-dependent apoptosis. Proc Natl Acad Sci USA 94: 2345-2349, 1997.

26. Selvakumaran M, Lin HK, Miyashita T, Wang HG, Krajewski S, Reed JC, Hoffman B and Liebermann D: Immediate early up-regulation of bax expression by $\mathrm{p} 53$ but not TGF beta 1: a paradigm for distinct apoptotic pathways. Oncogene 9: 1791-1798, 1994.

27. Llambi $\mathrm{F}$ and Green DR: Apoptosis and oncogenesis: give and take in the BCL-2 family. Curr Opin Genet Dev 21: 12-20, 2011.

28. Miyashita T, Krajewski S, Krajewska M, Wang HG, Lin HK, Liebermann DA, Hoffman B and Reed JC: Tumor suppressor p53 is a regulator of bcl-2 and bax gene expression in vitro and in vivo. Oncogene 9: 1799-1805, 1994. 